\title{
Islet Cell Antibodies Predict Insulin-dependent Diabetes in United States School Age Children as Powerfully as in Unaffected Relatives
}

\author{
Desmond Schatz, ${ }^{*}$ Jeffrey Krischer, ${ }^{\star}$ Gwen Horne, William Riley, ${ }^{\star}$ Rebecca Spillar, ${ }^{*}$ Janet Silverstein, ${ }^{\star}$ William Winter, ${ }^{*}$ \\ Andrew Muir, * Deborah Derovanesian, * Shirish Shah," John Malone," and Noel Maclaren ** \\ Departments of * Pathology and Laboratory Medicine and ${ }^{\ddagger}$ Pediatrics, University of Florida, Gainesville, Florida 32610; and \\ ${ }^{\S}$ Department of Pediatrics, University of South Florida, Tampa, Florida 33620
}

\begin{abstract}
Islet cell antibodies (ICA) in the sera of nondiabetic relatives of patients with insulin-dependent diabetes (IDD) are predictive of the disease, a finding that permits the design of intervention strategies to prevent it. However, $85 \%$ or more of patients with new onset IDD have no affected relative. We therefore screened 9,696 schoolchildren between the ages of 5 and $18 \mathrm{yr}$ (mean age 10.7 yr) in Pasco County, Florida for ICA in three surveys during 1984/5, 1987/8, and 1990/1 and have followed them prospectively. Approximately 4,000 of these children have been followed for nearly 8 yr. ICA titers $\geq 10$ Juvenile Diabetes Foundation units on replicate tests were detected in 57 of the children $(0.59 \%)$. 10 children have developed diabetes so far, and all had ICA detected beforehand. The likelihood of developing IDD among the ICA-positive children was compared with 2,959 age-matched nondiabetic first degree relatives of IDD probands who were screened for ICA by our laboratory during the same time period and also followed prospectively. Of 103 (3.5\%) ICA-positive relatives, 31 have developed IDD. Life table analysis reveals no statistically significant differences in the probability of developing IDD between the ICApositive schoolchildren and ICA-positive first degree relatives $(P=0.3)$. The estimated risk of developing IDD by $7 \mathrm{yr}$ in the ICA-positive schoolchildren was $45 \%$ (95\% confidence interval $15-74 \%$ ) compared with $43 \%$ (confidence interval $22-63 \%$ ) in the relatives. We conclude that ICA appear to be as predictive of IDD in low-risk schoolchildren as they are in high-risk relatives. These data suggest that it is feasible to predict IDD by screening a general population of schoolchildren for ICA and that those found to be positive could be considered, in addition to relatives, for intervention protocols to prevent the disease. (J. Clin. Invest. 1994. 93:2403-2407.) Key words: islet cell antibodies $\bullet$ insulin autoantibodies $\bullet$ insulin-dependent diabetes - schoolchildren • human leukocyte antigen
\end{abstract}

Address correspondence to Noel Maclaren, M.D., Department of Pathology and Laboratory Medicine, University of Florida College of Medicine, Box 100275, Gainesville, FL 32610. W. Riley and R. Spillar's current address is Department of Pediatrics, University of Texas Medical School at Houston, Houston, TX 77030.

Received for publication 28 September 1993 and in revised form 7 January 1994.

J. Clin. Invest.

(c) The American Society for Clinical Investigation, Inc.

$0021-9738 / 94 / 06 / 2403 / 05 \$ 2.00$

Volume 93, June 1994, 2403-2407

\section{Introduction}

Insulin-dependent diabetes (IDD) ${ }^{1}$ is a chronic autoimmune disease resulting from immunologically mediated destruction of the insulin-producing pancreatic beta cells, beginning often years before its clinical onset $(1,2)$. The detection of islet cell cytoplasmic autoantibodies (ICA) in the sera of nondiabetic relatives of patients with IDD identifies those most at risk for the disease $(3,4)$. High titered ICA, their presence in children rather than in adults, and the additional presence of insulin autoantibodies (IAA) in the sera of such patients all increase the risk of IDD associated with ICA (4-9). Autoantibodies to the $64,000-M_{\mathrm{r}}$ islet cell protein (recently identified to be the lower molecular weight isoform of glutamic acid decarboxylase $\left.\left[\mathrm{GAD}_{65}\right]\right)$ are the most often detectable autoantibodies before diagnosis $(10,11)$.

Whereas these reported studies have been performed in high risk relatives, IDD occurs sporadically in $>85 \%$ of patients who have no affected family member (12). Since the ability to identify impending IDD is an obvious and necessary prerequisite to the design of intervention trials to prevent or delay the onset of clinical disease, we tested the feasibility of using the IDD-associated autoantibodies to screen a general school age population to determine their risk of developing IDD (13). Younger school aged children were targeted for these studies because of the well known pubertal peak incidence of IDD.

\section{Methods}

\section{Patients}

School population. Children were recruited from schools in the mixed rural-urban Pasco County, in midwest Florida (Table I). In 1984, the county had 19,297 children enrolled in elementary or middle schools. We requested the participation of 8,691 school children between the ages of 5 and $17 \mathrm{yr}$ through questionnaires and informed consent forms taken home by the children to their parents. Blood samples (5-7 ml) were obtained from $4,873(56.1 \%)$ of these children. Another 10 $(0.11 \%)$ had documented IDD already and were not studied. In 1987, 3 $\mathrm{yr}$ after the initial survey, 2,052 (42.0\%) of the original ICA-negative children were retested together with a further 1,594 who had not been tested previously. During 1990/1, 1,111 of the children who had been tested at least once before for ICA and found to be negative were retested, while an additional 3,231 who had not been studied before had ICA determined for the first time. Children in whom ICA were detected were asked to have a second blood test for confirmation. Once the ICA were confirmed, arrangements were then made for serial intra-

1. Abbreviations used in this paper: $\mathrm{CI}$, confidence interval; IAA, insulin autoantibodies; ICA, islet cell antibodies; IDD, insulin-dependent diabetes; JDF, Juvenile Diabetes Foundation. 
Table I. Characteristics of the Study Population

\begin{tabular}{lcc}
\hline & Schoolchildren & First degree relatives \\
\hline$n$ & 9696 & 2959 \\
Age range $(y r)$ & $5-17$ & $5-17$ \\
Mean age $( \pm$ SD) $(y r)$ & $10.7(2.9)$ & $11.1(3.6)$ \\
Male/female ratio & $0.95: 1$ & $1: 1$ \\
Ethnic origin & & \\
White & $9247(95.4 \%)$ & $2768(93.6 \%)$ \\
Black & $139(1.4 \%)$ & $87(3.1 \%)$ \\
Hispanic & $199(2.1 \%)$ & $80(2.7 \%)$ \\
Other & $107(1.1 \%)$ & $22(0.8 \%)$ \\
Unknown & $4(-)$ & $2(-)$ \\
Maximum follow-up & $8.2 \mathrm{yr}$ & $13.3 \mathrm{yr}$ \\
& & \\
\hline
\end{tabular}

venous glucose tolerance testing, further autoantibody studies, and HLA-DR serological typing. According to the protocol, children who had a negative ICA result, were either contacted by mail or attempts were made to reach them or their families by telephone biannually to ascertain whether IDD had developed or not. Area pediatricians and regional hospitals were also contacted to request information on any child in our study who might have developed IDD during the observation period, thereby minimizing the chances that any of the study subjects could have developed diabetes without our knowledge.

Altogether 9,696 individual schoolchildren were screened for ICA in the three surveys with follow-up data (a second blood test for ICA or a telephone follow-up to exclude the presence of diabetes) available on $3,854(40 \%)$ who were followed between 2 and $8 \mathrm{yr}$ afterwards.

First degree relatives. In our natural history cohort study, 2,959 age-matched first degree relatives between 5 and $17 \mathrm{yr}$ of age (mean age $11.1 \mathrm{yr}$ ) were tested serially for ICA (14). Of these, 1,394 have been followed for up to $13 \mathrm{yr}$.

All studies were approved by the Institutional Review Board at the University of Florida.

\section{Laboratory evaluation}

ICA. ICA were determined by indirect immunofluorescence as described previously (6). All sera testing positive for ICA were titered to an end point dilution, and the results were expressed in Juvenile Diabetes Foundation (JDF) units by comparison with a standard reference serum from the Immunology of Diabetes Workshops $(14,15)$. The endpoint titer of the JDF standard was defined at the initial workshop as $80 \mathrm{JDF}$ units. The coefficients of variability between assays for control sera with $20,40,80,160$, and 320 JDF units tested in 10 consecutive assays were $7,9,4,5$, and $6 \%$, respectively, when expressed geometrically (SD $\log _{2}$ JDF units/mean $\log _{2} \mathrm{JDF}$ units). In the 4th International Islet Cell Antibody Workshop, our laboratory was both $100 \%$ sensitive and specific as determined in blinded analyses of test sera. The threshold of ICA detection in our laboratory was 5 JDF units. Only ICA of 10 or more JDF units were considered positive.

$I A A$. IAA were determined by radioimmunoassay as described previously (16), except that a human ${ }^{125} \mathrm{I}$-labeled monospecific A14 insulin ligand was used, as generously provided by Eli Lilly \& Co. (Indianapolis, IN). This method measured the maximal displaceable insulin binding expressed in nanounits per milliliter. The insulin-binding values of 83 healthy controls, which were part of the 1990 Immunology of Diabetes Workshop distribution of sera for the Third International Insulin Antibody Workshop (17), were used to define our normal range ( mean $+3 \mathrm{SD} \leq 109 \mathrm{nU} / \mathrm{ml})$. Of two positive quality control sera with mean IAA values of 740 and $144 \mathrm{nU} / \mathrm{ml}$, the interassay coefficients of variation were 12 and $17 \%$, respectively. From an independent analysis of the results of the proficiency program, our assay was
Table II. Prevalence of IDD-associated Autoantibodies

\begin{tabular}{lccc}
\hline & Schoolchildren & $\begin{array}{c}\text { First degree } \\
\text { relatives }\end{array}$ & $P$ value \\
\hline Total number & 9696 & 2959 & \\
ICA $\geq 10 \mathrm{JDF}$ units & $57(0.59 \%)$ & $103(3.5 \%)$ & $<0.001$ \\
IAA $>109 \mathrm{nU} / \mathrm{ml}$ & $31 / 2782(1.1 \%)$ & $86 / 2399(3.6 \%)$ & $<0.001$ \\
$\begin{array}{l}\text { ICA } \geq 10 \mathrm{JDF} \text { units } \\
\text { and IAA }>\end{array}$ & & & \\
$109 \mathrm{nU} / \mathrm{ml}$ & $11 / 2782(0.4 \%)$ & $43 / 2399(1.8 \%)$ & $<0.001$ \\
\hline
\end{tabular}

found to be highly specific (93\%) and among the most sensitive (100\%) of the laboratories submitting results.

$H L A-D R$ typing. HLA-DR typing was offered to all children who tested positive for ICA as well as to a comparative group of ICA-negative schoolchildren. This latter group comprised children who were retested for ICA and had been screened as negative initially. A standard double immunofluorescence assay was used (18). HLA-DR typings were also performed on as many of the autoantibody-positive relatives as possible. Antisera used to type for HLA-DR alleles were purchased from One Lambda Laboratories (Los Angeles, CA).

\section{Biostatistical analyses}

The prognostic significance of ICA was determined from the time of the blood sampling at which titers $\geq 10$ JDF units were found. IAA positivity was defined at the first occurrence of insulin ligand binding by a serum sample of $>109 \mathrm{nU} / \mathrm{ml}$. Similarly, the length of follow-up and the duration of ICA and/or IAA positivity were calculated from the time of the first positive test. The method of Kaplan and Meier (19) was used to construct life tables of the likelihood of developing IDD, and the log rank test was used to compare them (20). When frequencies were sufficiently large, the Chi-square statistic was used to compare proportions. Otherwise, an exact test of proportions was used (21). A two-tail $P$ value of 0.05 was established for statistical significance.

\section{Results}

Of the 9,696 schoolchildren screened for ICA since 1984, ICA were present in the sera of $57(0.59 \%)$ (Table II). 10 children $(0.1 \%)$ have developed IDD by the time of writing and all of them were ICA positive at screening (Tables III and IV).

Of the 2,959 nondiabetic first degree relatives of IDD subjects tested for ICA during this time period, $1,394(47 \%)$ have been prospectively followed. ICA titers of $10 \mathrm{JDF}$ units or greater were found in $103(3.5 \%)$ of the children. IDD has subsequently developed in $40(2.7 \%)$ of the relatives for whom follow-up data was available.

Table III. 5-Yr Risk of Developing IDD

\begin{tabular}{lllc}
\hline & Schoolchildren & $\begin{array}{c}\text { First degree } \\
\text { relatives }\end{array}$ & $P$ value \\
\hline All & $0.4 \%\left(<0.1^{*}\right)$ & $2.8 \%(0.7)$ & $<0.0001$ \\
ICA $\geq 10 \mathrm{JDF}$ units & $28 \%(10)$ & $38 \%(8)$ & 0.3 \\
$\begin{array}{l}\text { ICA } \geq 10 \mathrm{JDF} \text { units } \\
\text { and IAA }> \\
109 \mathrm{nU} / \mathrm{ml}\end{array}$ & & & \\
& $43 \%(37)$ & $34 \%(13)$ & 0.4 \\
\hline
\end{tabular}

* SE. 
Table IV. Characteristics of Schoolchildren Progressing to IDD

\begin{tabular}{|c|c|c|c|c|c|c|c|}
\hline & $\begin{array}{c}\text { Age at } \\
\text { screening }\end{array}$ & Sex & $\begin{array}{l}\text { Relative } \\
\text { with IDD }\end{array}$ & Peak ICA & IAA & HLA-DR & Duration to IDD \\
\hline & $y r$ & & & JDF units & $n U / m l$ & & $y r$ \\
\hline R. P. & 7.7 & $\mathbf{M}$ & - & 10 & Neg & Not done & 4.4 \\
\hline B. B. & 7.5 & $\mathbf{M}$ & - & 40 & 3581 & 0,4 & 4.3 \\
\hline R. N. & 7.9 & $\mathbf{M}$ & - & 80 & $\mathrm{Neg}$ & 4,0 & 1.2 \\
\hline D. R. & 10 & $\mathbf{F}$ & Father & 640 & 502 & 3,4 & 3.6 \\
\hline R. M. & 13.5 & $F$ & - & 320 & $\mathrm{Neg}$ & 4,6 & 6.8 \\
\hline L. B. & 15.6 & $\mathbf{M}$ & - & 20 & $\mathrm{Neg}$ & 4,8 & 7.1 \\
\hline B. Y. & 7.9 & $\mathbf{M}$ & - & 160 & 353 & 3,4 & 6.2 \\
\hline B. $\mathbf{R}$. & 9.5 & $\mathbf{F}$ & - & 160 & 145 & 1,4 & 0.3 \\
\hline D. N. & 7.0 & $\mathrm{~F}$ & - & 40 & Neg & 3,1 & 6.8 \\
\hline K. B. & 8.4 & $\mathbf{F}$ & - & 40 & 145 & 1,8 & 2.0 \\
\hline
\end{tabular}

IAA were performed on 2,399 of the 2,672 children ( $81 \%$ ) of first degree relatives and 2,782 schoolchildren (29\%). Although the frequency of IAA was significantly higher $(P<$ $0.001)$ in the relatives $(86 / 2,399 ; 3.6 \%)$ compared with schoolchildren $(31 / 2,782 ; 1.1 \%)$, the frequencies of IAA in the ICA-positive children of both groups were not statistically different ( 47 vs $20 \% ; P=0.10$ ).

By life table analysis, the estimated risk for the development of IDD in the ICA-positive schoolchildren was $28 \%$ (confidence interval [CI] 7-52\%) at $5 \mathrm{yr}$ and $45 \%$ (CI 15-74\%) at 7 yr. This was similar to matched ICA-positive first degree relatives (38 [CI 23-52\%] and 43\% [CI 22-63\%] $P=0.3$ ) (Fig. 1 and Table III). As we had reported previously for ICA-positive relatives, the additional presence of IAA in the sera of ICA-positive schoolchildren increased the risk of their subsequent development of IDD $(P=0.009)$. The presence of both ICA and IAA in 11 of the schoolchildren was just as predictive of their subsequent development of IDD (43\%) at $5 \mathrm{yr}$ as it was in 43 first degree relatives (34\%; $P=0.4$ ) at 5 yr (Fig. 2 and Table III). IAA without ICA were present in the sera of $0.7 \%$ of schoolchildren tested on follow-up. None have developed IDD. In 43 unaffected relatives of IDD subjects who have IAA alone, the risk of developing diabetes at $5 \mathrm{yr}$ was $14 \%$ (SE 15\%).

Those ICA-positive schoolchildren who subsequently developed IDD were most likely to be DR3/4 heterozygotes or have the high IDD risk DR3 or DR4 alleles compared with those who did not ( $P=0.02$; Fig. 3 and Table IV). The only ICA-positive subject who developed IDD but lacked DR3 and DR4 alleles had the IDD high-risk DR $1 / 8$ phenotype. These data, as expected, are similar to other patients with documented IDD that our laboratory has studied (18). 19 of the remaining 31 ICA-positive subjects (61\%) had either the DR3 and/or DR4 alleles, supporting their greater risk for the subsequent development of disease. As seen in Fig. 3, the risk of developing diabetes in both ICA-positive schoolchildren and relatives who typed HLA-DR3 and/or -DR4 positive was $\sim 50 \%$ at $7 \mathrm{yr}$, while the risk of IDD in subjects who did not have either the DR3 or DR4 allele was comparatively lower.

\section{Discussion}

Our prospective study documents that it is not only feasible to predict IDD among a general population of schoolchildren, but that the rate of progression to IDD in ICA-positive subjects with a titer $\geq 10$ JDF units is similar to that found in first degree relatives of IDD probands. We found ICA titers $\geq 10$ JDF units to be present in $0.59 \%$ of schoolchildren, which is a frequency that is about twice the reported prevalence of IDD in the general population (12). These ICA frequency data relative to that of IDD are similar to those reported in the general

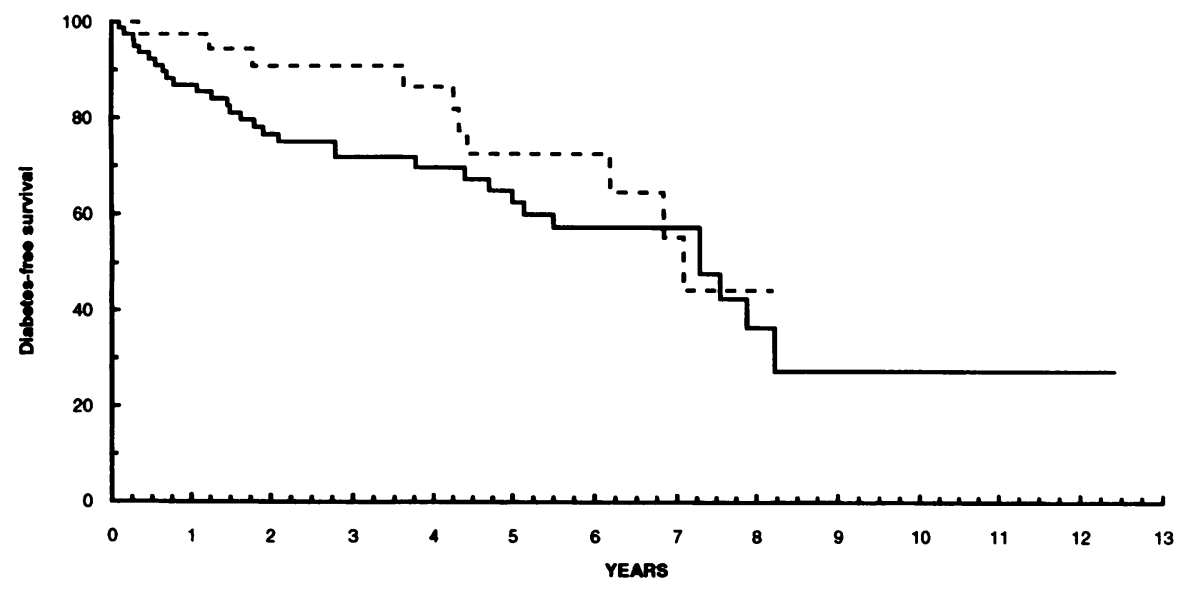

Figure 1. Probability of remaining IDDfree comparing 103 relatives and 57 schoolchildren aged 5-17 yr who tested positive for ICA. Solid line, relatives; broken line, schoolchildren. 


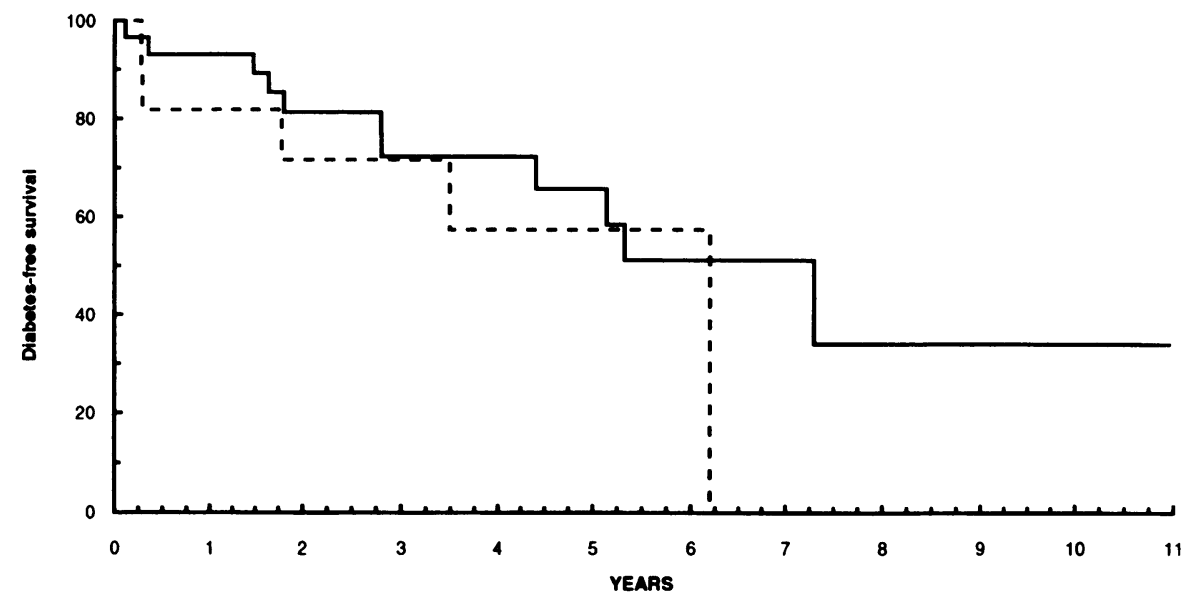

Figure 2. Probability of remaining IDDfree comparing 43 relatives with 11 schoolchildren who tested positive for ICA and IAA. Solid line, relatives; broken line, schoolchildren. populations of Holland (22), Spain (23), Japan (24), and New Zealand (Bob Elliott, personal communication).

Most other studies have reported frequencies of ICA in the general population that far exceed the prevalence of the disease. These include a recent Swedish study in which the frequency of ICA in control children was 3\% (25), with a diabetic prevalence of $0.15 \%$ (26). Similar ICA frequencies of $4 \%$ were found in a study of 1,218 schoolchildren in Finland (27), 2.2\% in 540 children in the United Kingdom (28), and $1.8 \%$ in 8,363 French schoolchildren (29). Several explanations for ICA frequencies that are higher than those we report here are possible. Unusually high IDD prevalence rates are present in northern European countries, particularly Scandinavia. Further, the limits for detection for ICA in those studies were reported to be as low as 1 JDF unit. Since ICA titers $<10 \mathrm{JDF}$ units in nondiabetic relatives often disappear with time, are not reliably reproducible in replicate assays, and are poorly predictive of subsequent progression to disease, we chose to raise our detection level of ICA accordingly $(14,29)$. The lower limit of ICA detection was set at $5 \mathrm{JDF}$ units, and only those ICA levels $\geq 10$ JDF units were considered positive. Although ICA standardization should allow for valid comparisons between laboratories who are screening for diabetes, there is still considerable variations in the sensitivity and precision of the ICA assay in most investigators' hands, especially at the lower detection lim- its $(30,31)$. In addition, population size and duration of follow-up are crucial variables.

The additional presence of IAA in the sera of ICA-positive schoolchildren increased the predictability of the disease, as has been reported in ICA-positive first degree relatives (14). The presence of IAA by itself in the sera of the schoolchildren, however, did not convey any detectable increased risk for the subsequent development of IDD, which is consistent with the low predictability of IAA alone reported in first degree relatives of IDD subjects (14). Antibodies to the islet cell $64,000-M_{\mathrm{r}}$ protein were present in seven out of seven ICA-positive schoolchildren so studied who had progressed to diabetes. Since these autoantibodies are highly predictive of the prediabetic state in nonaffected relatives $(10,32)$, their value as a screening tool is promising, but needs to be proven.

A genetic predisposition should exist in those ICA-positive schoolchildren destined to develop IDD. The frequencies of the HLA-DR3 and/or -DR4 IDD-related phenotypes in the ICA schoolchildren were increased in those ICA-positive subjects who subsequently developed IDD, as has been reported previously for ICA-positive relatives of patients with IDD(14). These data suggest that HLA-DR testing may be helpful in predicting which ICA-positive subjects will subsequently develop disease. Presumably, DQ molecular typing will even further improve this predictive ability.

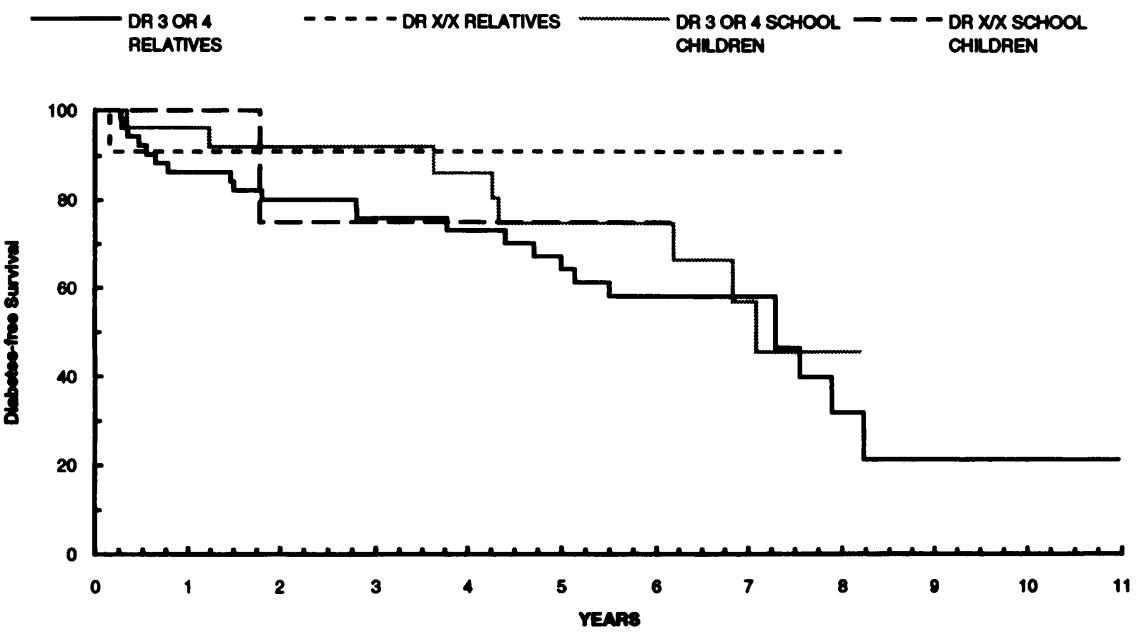

Figure 3. Probability of remaining IDDfree comparing HLA-DR typing of 64 relatives ( 53 DR 3 or 4 , or $3 / 4$ ) and 41 schoolchildren ( 27 DR 3 or 4 , or $3 / 4$ ) who tested positive for ICA. ICA-positive subjects who had no DR3 or 4 alleles had a very low risk of developing diabetes. 
In summary, in this prospective study over a period now approaching a decade, we report that ICA titers $\geq 10 \mathrm{JDF}$ units in a general population of United States schoolchildren are predictive of the subsequent development of IDD, in a quantitative manner similar to that found in first degree relatives of IDD subjects. The added presence of IAA and IDD-associated HLA-DR3 and/or -DR4 alleles further increases the predictability of IDD. These data confirm the validity of ICA to predict IDD in a general population as well as in relatives genetically predisposed to the development of IDD. The comparison of the risks of IDD in ICA-positive schoolchildren versus relatives should be interpreted with the caveat that the relatively small numbers in our study provide $80 \%$ power to detect a $25 \%$ or greater difference in the risk of developing IDD and that smaller differences could have gone undetected. Although the yield of positive ICA tests in population screening relative to unaffected first degree relatives is relatively low, such subjects should be included when planning intervention trials.

\section{Acknowledgments}

We would like to express our thanks to the Pasco County School Board, their teachers and staff, and the Tampa chapter of the JDF that made the study possible.

This study was supported in part by grants (RO1 HD 19469; POI DK 39079; RCDA KO4 AM01421; and GCRC, MO1 RR00082) from the National Institutes of Health and a gift from Sidney Kriser.

\section{References}

1. Maclaren, N. K., D. A. Schatz, A. L. Drash, and G. Grave. 1989. The initial pathogenic events in insulin dependent diabetes. Diabetes. 38:534-538.

2. Gorsuch, A. N., K. M. Spencer, J. Lister, J. M. McNally, B. M. Dean, G. F. Bottazzo, and A. G. Cudworth. 1981. Evidence for a long latent period in type 1 (insulin dependent) diabetes mellitus. Lancet. ii:1363-1365.

3. Srikanta, S., O. P. Ganda, A. Rabizadeh, J. S. Soeldner, and G. S. Eisenbarth. 1985. First degree relatives of patients with type 1 diabetes mellitus: islet cell antibodies and abnormal insulin secretion. N. Engl. J. Med. 313:461-464.

4. Tarn, A. C., J. M. Thomas, B. M. Dean, D. Ingram, G. Schwarz, G. F. Bottazzo, and E. A. Gale. 1988. Predicting insulin dependent diabetes. Lancet. i:845-850.

5. Bonifacio, E., P. J. Bingley, M. Shattock, B. M. Dean, D. Dunger, E. A. Gale, and G. F. Bottazzo. 1990. Quantitation of islet cell antibodies and prediction of insulin dependent diabetes. Lancet. 335:147-149.

6. Riley, W. J., N. K. Maclaren, J. P. Krischer, R. P. Spillar, J. H. Silverstein, D. A. Schatz, S. Shah, C. M. Vadheim, and J. I. Rotter. 1991. A prospective study of the development of diabetes in relatives of patients with insulin dependent diabetes. N. Engl. J. Med. 323:1167-1172.

7. Atkinson, M. A., N. K. Maclaren, W. J. Riley, W. E. Winter, D. Fisk, and R. P. Spillar. 1986. Are insulin autoantibodies markers for insulin dependent diabetes mellitus? Diabetes. 35:894-889.

8. Betterle, C., F. Presotto, B., Pedini, L. Moro, R. Slack, F. Zanette, and R. Zanchetta. 1987. Islet cell and insulin autoantibodies in organ specific autoimmune patients. Their behavior and predictive value for the development of type 1 diabetes mellitus. A 10 year follow up study. Diabetologia. 30:292-297.

9. Soeldner, J. S., M. Tuttleman, S. Srikanta, O. P. Ganda, and G. S. Eisenbarth. 1985. Insulin dependent diabetes mellitus and initiation of autoimmunity: islet cell autoantibodies, insulin antibodies and beta cell failure. $N$. Engl. J. Med. 313:893-894.

10. Atkinson, M. A., N. K. Maclaren, D. W., Scharp, P. E. Lacy, and W. J. Riley. 1990. 64,000 $\mathrm{M}_{\mathrm{r}}$ autoantibodies as predictors of insulin dependent diabetes. Lancet. 335:1357-1360.

11. Baekkeskov, S., H.-J. Aanstoot, S. Christgau, A. Reetz, M. Solimena, M.
Cascalho, F. Foili, H. Richter-Olesen, and P. De Camilli. 1990. Identification of the $64 \mathrm{~K}$ autoantigen in insulin-dependent diabetes as the GABA-synthesizing enzyme glutamic acid decarboxylase. Nature (Lond.). 347:151-156.

12. La Porte, R. E., and K. J. Cruickshanks. 1988. Incidence and risk factors for insulin dependent diabetes. In Diabetes in America. National Diabetes Data Group. National Institutes of Health Publication No. 85-1468. 3:1-12.

13. Maclaren, N. K. 1988. How, when, and why to predict IDDM. Diabetes. 37:1591-1594.

14. Krischer, J. P., D. A. Schatz, W. J. Riley, R. P. Spillar, J. H. Silverstein, S Schwartz, J. Malone, S. Shah, C. M. Vadheim, J. I. Rotter, et al. 1993. Insulin and islet cell antibodies as time dependent covariates in the development of insulin dependent diabetes: a prospective study in relatives. J. Clin. Endocrinol. \& $\mathrm{Me}$ tab. 77:743-749.

15. Bonifacio, E., A. Lernmark, and R. L. Dawkins. 1988. Serum exchange and use of dilutions have improved precision of measurement of islet cell antibodies. J. Immunol. Methods. 106:83-88.

16. Vardi, P., S. A. Dib, M. Tuttleman, J. E. Connelly, M. Grinbergs, W. J. Riley, N. K. Maclaren, G. S. Eisenbarth, and J. S. Soeldner. 1987. Competitive insulin autoantibody RIA. Prospective evaluation of subjects at high risk for development of Type 1 diabetes mellitus. Diabetes. 36:1286-1291.

17. Palmer, J. P., T. J. Wilkin, A. B. Kurtz, and E. Bonifacio. 1990. The Third International Workshop on the standardization of insulin autoantibody measurement. Diabetologia. 33:60-61.

18. Maclaren, N. K., W. J. Riley, N. Skordis, M. A. Atkinson, R. P. Spillar, J. H. Silverstein, R. Klein, and J. I. Rotter. 1988. Inherited susceptibility to insulin dependent diabetes is associated with HLA-DR1 while DR-5 is protective. Autoimmunity. 1:45-50.

19. Kaplan, E., and P. Meier. 1958. Nonparametric estimation from incomplete observations. JASA (Journal of American Statistical Association). 53:457481 .

20. Mantal, N. 1966. Evaluation of survival data and two new rank order statistics arising in its consideration. Cancer Chemother. Rep. 50:163-170.

21. Schuster, J. 1988. EXACTB and CONF: exact unconditional procedures for binomial data. American Statistician. 42:234.

22. Bruining, G. J., J. L. Molenaar, D. E. Grobbee, A. Hofman, G. J. Scheffer, H. A. Bruining, A. M. de-Bruyn, and H. A. Valkenburg. 1989. Ten year follow up study of islet cell antibodies and childhood diabetes mellitus. Lancet. i:11001102.

23. Bergua, M., J. Sole, G. Marion, M. C. Perez, A. Recasens, J. Fernandez, R. Casmitjana, and R. Gomis. 1987. Prevalence of islet cell antibodies, insulin antibodies and hyperglycemia in 2,291 school children. Diabetologia. 30:724-726.

24. Notsu, K., N. Oka, S. Note, N. Nabeya, S. Kuno, and T. Sakurami. 1985. Islet cell antibodies in the Japanese population and in subjects with Type 1 (insulin-dependent) diabetes. Diabetologia. 28:660-662.

25. Landin-Olsson, M., J. P. Palmer, A. Lernmark, L. Blom, G. Sundkvist, L. Nystrom, and G. Dahlquist. 1992. Predictive value of islet cell and insulin autoantibodies for Type 1 (insulin-dependent) diabetes mellitus in a population-based study of newly-diagnosed diabetic and matched control children. Diabetologia. 35:1068-1073.

26. Dahlquist, G., K. H. Gustavsson, G. Holmgren, B. Hagglof, Y. Larsson, K. O. Nilsson, G. Samuelson, G. Sterky, B. Thalme, and S. Wall. 1982. The incidence of diabetes mellitus in Swedish schoolchildren 0-14 years of age. A prospective study 1977-1980. Acta Pediatr. Scand. 71:7-14.

27. Karjalainen, J. K. 1990. Islet cell antibodies as predictive markers for insulin-dependent diabetes mellitus in children with high background incidence of disease. Diabetes. 39:1144-1150.

28. Bingley, P. J., E. Bonifacio, and E. A. M. Gale. 1993. Can we really predict IDDM? Diabetes. 42:213-220.

29. Levy-Marchal, C., J. Tichet, I. Fajardy, X. F. Gu, F. Dubois, and P. Czernichow. 1992. Islet cell antibodies in normal French schoolchildren. Diabetologia. 35:577-582.

30. Bonifacio, E., C. Boitard, H. Gleichman, M. A. Shattock, J. L. Molenaar, and G. F. Bottazzo. 1990. Assessment of precision, concordance, specificity, and sensitivity of islet cell antibody measurement in 41 assays. Diabetologia. 33:731736.

31. Greenbaum, C. J., J. P. Palmer, S. Nagataki, Y. Yamaguchi, J. L. Molenaar, W. A. M. Van Beers, N. K. Maclaren, and A. Lernmark. 1992. Improved specificity of ICA assays in the Fourth International Immunology of Diabetes serum exchange workshop. Diabetes. 41:1570-1574.

32. Barmeier, H., D. K. McCulloch, J. L. Neifing, G. Warnock, R. V. Rajotte J. P. Palmer, and A. Lernmark. 1992. Risk for developing type 1 (insulin-dependent) diabetes mellitus and the presence of islet $64 \mathrm{~K}$ antibodies. Diabetologia. 34:727-733. 